\title{
Erratum to: Children's Adjustment and Child Mental Health Service Use: The Role of Parents' Attitudes and Personal Service Use in an Upper Middle Class Sample
}

\author{
Erlanger A. Turner $\cdot$ Jeffrey Liew
}

Published online: 16 September 2009

(C) Springer Science+Business Media, LLC 2009

\section{Erratum to: Community Ment Health J \\ DOI 10.1007/s10597-009-9221-8}

In the Methods section describing parental education, "a middle school education" should be read as "a 2-year college or high school education".
Among parents, $81 \%$ identified as Caucasian or NonHispanic White, $12 \%$ identified as Hispanic American, and $7 \%$ identified as other. In regard to education, $47.5 \%$ had a graduate (masters or doctoral) degree, $40 \%$ had bachelor's degree, and $12.5 \%$ had a 2 -year college or high school education.

The online version of the original article can be found under doi:10.1007/s10597-009-9221-8.

E. A. Turner

Department of Psychology, College of Liberal Arts,

Texas A\&M University, College Station, TX, USA

J. Liew ( $\square)$

Department of Educational Psychology, College of Education and Human Development, Texas A\&M University,

4225 TAMU, College Station, TX 77843-4225, USA

e-mail: jeffrey.liew@tamu.edu 